\section{Identification of the Female Sex Pheromone of the Rice Green Caterpillar}

\author{
Tetsu Ando, Ken-ichi Kishino,* \\ Sadahiro TATSUKI,** \\ Hiromitsu NaKajima, Sigeo Yoshida \\ and Nobutaka TAKAHASHI \\ Department of Agricultural Chemistry, Faculty \\ of Agriculture, The University of Tokyo, \\ Tokyo 113 \\ *Tohoku National Agricultural Experiment \\ Station, Omagari, Akita 014-01 \\ **The Institute of Physical and Chemical \\ Research, Wako, Saitama 351
}

Received June 16, 1977

The rice green caterpillar, Naranga aenescens Moor (Lepidoptera: Noctuidae, Eustrotiinae), is one of the most harmful pest insects of rice plant in eastern Asia. The effective synthetic sex pheromone of this insect is required in integrated pest control programs, either as a monitoring tool for timing insecticide application or as an insect control tool.

In our preliminary study, it was confirmed that the virgin female produces the sex pheromone which attracts the male moths in the field, and the following chemical nature of the pheromone was disclosed by the combination of preliminary chemical reactions and field tests. The attractive activity of the crude extract was lost after treatment with methanolic potassium hydroxide, but treatment of the crude saponified mixture with $\mathrm{Ac}_{2} \mathrm{O}$-pyridine restored the original activity. Hydrogenation of the pheromone over $\mathrm{PtO}_{2}$ eliminated the attractive activity. Thus the pheromone was suggested to be acetate of unsaturated alcohol.

In our field sex attractant-tests for lepidoptera using synthetic compounds, about onehundred monoene alcohols $\left(\mathrm{C}_{10}-\mathrm{C}_{18}\right)$ and their acetates were tested ${ }^{1 /}$ but none of them could attract $N$. aenescens when tested in a single source. On the other hand, in the assay by the electroantennogram (EAG) technique ${ }^{2)}$ this insect clearly responded to several acetates. This suggests that the sex pheromone of $N$. aenescens may have multi-components and/or polyene nature. On the basis of these findings, we decided to isolate and characterize EAGactive components at first and then to conduct field tests on these components to confirm whether they are necessary to attract the male moth or not.

The abdominal tips excised from 1200 virgin female moths were soaked in $n$-hexane for thirty minutes. The crude extract obtained by evaporation of the solvent was subjected to thin-layer chromatography (TLC) (silica gel; solvent: $n$-hexane-benzene (1:3)). EAG-active zone $(R f 0.4 \sim 0.5)$ was fractionated by gas-liquid chromatography (GC) (OV$12 \%, 3 \mathrm{~mm} \times 120 \mathrm{~cm}, 140^{\circ} \mathrm{C}$ ) to give two EAGactive fractions (Fractions $\mathrm{A}$ and $\mathrm{B}$ ). Fraction A was collected at $3.6 \sim 5.6 \mathrm{~min}$ and Fraction $B$ at $9.9 \sim 13.2 \mathrm{~min}$. (In this GC condition, retention times of tetradecanyl acetate and hexadecanyl acetate were $4.2 \mathrm{~min}$ and $10.4 \mathrm{~min}$, respectively.)

Gas liquid chromatography combined with mass spectroscopy (GC-MS) of Fraction A on a PEG $20 \mathrm{M}$ column showed one major peak which possessed the following fragment ions: $m / e 194\left(13 \%, \mathrm{C}_{14} \mathrm{H}_{26}{ }^{+}\right), 166(2 \%$, $\left.\mathrm{C}_{12} \mathrm{H}_{22}{ }^{+}\right), \quad 152\left(3 \%, \mathrm{C}_{11} \mathrm{H}_{20}{ }^{+}\right), 138 \quad(6 \%$, $\left.\mathrm{C}_{10} \mathrm{H}_{18}{ }^{+}\right), \quad 124 \quad\left(8 \%, \mathrm{C}_{9} \mathrm{H}_{16}{ }^{+}\right), \quad 110 \quad(18 \%$, $\left.\mathrm{C}_{8} \mathrm{H}_{14}{ }^{+}\right), 61(16 \%)$ and $43(100 \%$, base ion peak), indicating that the peak should be a tetradecenyl acetate. Similarly the mass spectrum of the major peak of Fraction B was shown to be a hexadecenyl acetate.

To determine the location of the double bond in these compounds, ozonolysis was conducted after a further purification of Fractions $\mathrm{A}$ and $\mathrm{B}$ by the $\mathrm{GC}$ fractionation with a PEG $20 \mathrm{M}$ column. GC-MS of the ozonolysis product of the purified Fraction A showed that one major component is 9-acetoxynonal in the respect of the retention time and the mass spectrum, while that of the purified Fraction B gave two peaks, which were shown to be due to 9-acetoxynonal (minor component) and 11-acetoxyundecanal (major component). 


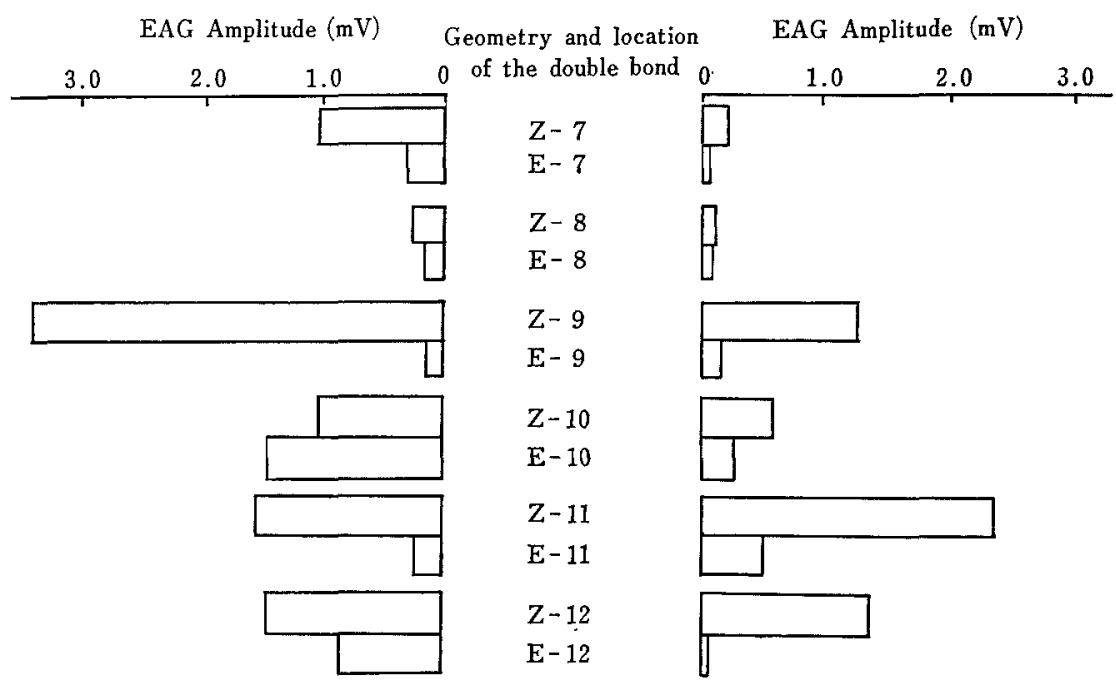

(a) Tetradecenyl acetate

(b) Hexadecenyl acetate

FIG. 1. EAG Activity to Monoene Acetates, $10 \mu \mathrm{g} /$ cartridge.

TLC of the crude extract on $20 \% \mathrm{AgNO}_{3} /$ silica gel plates using benzene as developing solvent and subsequent EAG analysis showed activity only at Z-monoene acetate zone $(R f$ $0.4 \sim 0.5$ ). (E-monoene; $R f$ ca. 0.6, E, Zdiene; $R f$ ca. 0.3.)

Thus the EAG-active components in $N$. aenescens virgin female were characterized as Z-9-tetradecenyl acetate (compound I), Z-9hexadecenyl acetate (compound II) and Z-11hexadecenyl acetate (compound III). By the $\mathrm{GC}$ analysis, it was observed that the extract contained compounds I, II and III in the ratio of $1: 1: 4$, respectively.

EAG activities of several isomers of tetradecenyl acetates and hexadecenyl acetates are shown in Fig. 1. Synthetic specimens of compound I $\sim$ III showed clear EAG responses, furnishing the strong support for the above identification. Further, stronger responses of Z-isomers than E-isomers are in good agreement with our assignment of geometry of the double bond.

Field trials to the synthetic pheromones are in progress. However, in preliminary experi- ment it has been demonstrated that only the mixture of the three compounds could attract the male moths. The optimum ratio of the attractant in the field is also being examined.

Compounds I and III have been known to be the sex pheromone of some other species in the family Noctuidae, but compound II has been identified as the pheromone for the first time. ${ }^{3 !}$

Acknowledgement. We thank Dr. Y. Tamaki of National Institute of Agricultural Sciences for his help in measuring GC-MS spectra and useful advice, and Ms. T. Sato of Tohoku National Agricultural Experiment Station for rearing of the insect.

\section{REFERENCES}

1) T. Ando, S. Yoshida, S. Tatsuki and N. Takahashi, Agric. Biol. Chem., 39, 1163 (1975); idem, ibid., 41, 1485 (1977).

2) W. L. Roelofs and A. Comeau, J. Insect Physiol,, 17, 1969 (1971).

3) M.S. Mayer and J. R. McLaughlin, "Florida Agricultural Experiment Stations Monograph Series No. 6, An Annotated Compendium of Insect Sex Pheromones," Institute of Food and Agricultural Sciences, University of Florida, Gainesville, 1975. 